\title{
Injuries in Bolivia: Initial Trauma Registry Results from Five Hospitals in Santa Cruz de la Sierra
}

\author{
${ }^{1}$ Marissa A Boeck, ${ }^{2}$ Samuel D South, ${ }^{3} \mathrm{~J}$ Esteban Foianini, ${ }^{4}$ German Toledo, ${ }^{5}$ Jose C Camacho, ${ }^{6}$ Oscar M Gutiérrez, \\ ${ }^{7}$ Lorena Jauregui, ${ }^{8}$ Pablo Mercado, ${ }^{9}$ Adil H Haider, ${ }^{10}$ Mamta Swaroop
}

\section{RESUMEN}

Título: Trauma en Bolivia: Resultados iniciales del registro de trauma de cinco hospitales en Santa Cruz de la Sierra

Objetivo: Trauma es una de las causas principales de muerte en el mundo. Muchos entornos con recursos limitados, como Bolivia, no tienen datos sobre los mecanismos y resultados de lesiones traumaticas, lo que restringe las iniciativas específicas de prevención y mejora en la calidad. Revisamos los resultados iniciales de cinco registros de trauma hospitalarios en Santa Cruz de la Sierra para explorar las características de las lesiones en esta región de Bolivia.

Materiales y métodos: Desde octubre del 2015 hasta mayo del 2016, el personal del departamento de urgencias (DU) recopiló información sobre los pacientes traumatizados, incluyendo datos demográficos personales y de las lesiones, datos prehospitalarios y su disposición del hospital, con la transferencia posterior a una plataforma virtual.

Resultados: El registro capturó $\mathrm{N}=3,220$ pacientes, de los cuales el $64 \%$ eran hombres de 21 años (RIC 6, 37). El transporte hospitalario se realizó a través de un automóvil privado

${ }^{1,2}$ General Surgery Resident, ${ }^{3}$ Medical Director, ${ }^{4,5,8}$ Director of ED, ${ }^{6,9}$ Director, ${ }^{7}$ Surgeon, ${ }^{10}$ Associate Professor

${ }^{1}$ Department of Surgery, New York Presbyterian Hospital, Columbia, New York

${ }^{2,10}$ Department of Division of Trauma and Critical Care, Northwestern University Feinberg School of Medicine, Chicago, Illinois

${ }^{3}$ Department of Surgery, Clinica Foianini, Santa Cruz de la Sierra, Santa Cruz, Bolivia

${ }^{4}$ Department of Emergency, Hospital San Juan de Dios, Santa Cruz de la Sierra, Santa Cruz, Bolivia

${ }^{5}$ Department of Emergency, Hospital Universitario Japonés, Santa Cruz de la Sierra, Santa Cruz, Bolivia

${ }^{6}$ Department of Emergency, Clinica Foianini, Santa Cruz de la Sierra, Santa Cruz, Bolivia

${ }^{7}$ Department of Surgery, Hospital de Niños Mario Ortiz Suarez, Santa Cruz de la Sierra, Santa Cruz, Bolivia

${ }^{8}$ Department of Emergency, Hospital Municipal Plan Tres Mil, Santa Cruz de la Sierra, Santa Cruz, Bolivia

${ }^{9}$ Department of Surgery, Center for Surgery and Public Health, Brigham and Women's Hospital, Boston, Massachusetts

Corresponding Author: Marissa A Boeck, General Surgery Resident, Department of Surgery, New York Presbyterian Hospital, Columbia, New York, United States, e-mail: marissaboeckMD@gmail.com
(37\%), taxi (23\%), o ambulancia (15\%), y muchos se presentaron el día de la lesión (74\%) y dentro de las primeras cuatro horas (52\%). La mayoría de las lesiones ocurrieron en el hogar $(38 \%)$ o en la calle $(29 \%)$, fueron contusos $(64 \%)$, y se debieron a caídas (43\%), incidentes de transito (13\%), o mordeduras de perros $(8 \%)$. Las lesiones clasificables $(\mathrm{N}=2,874)$ mas comunes incluyeron contusiones de cabeza/cara/extremidades (43\%), fracturas de extremidades (12\%), lesiones penetrantes de brazos/manos (3\%), y lesiones por mordedura a la cara (3\%). Los pacientes fueron dados de alta habitualmente desde el servicio de urgencias a domicilio (62\%) o fueron admitidos $(16 \%)$, y se reportaron seis fatalidades $(0.19 \%)$.

Conclusione: Estos datos sugieren que los pacientes con trauma que acuden a los hospitales del registro no son hospitalizados con frecuencia, y muchas lesiones se pueden prevenir. Una representación más completa del trauma dentro de la ciudad requiere una mejor calidad de los datos, la expansión de programa, y la inclusión de fuentes de datos complementarios. Los resultados servirán para informar al área de planificación de los recursos y de estrategias preventivas del sistema de salud, permitiendo intervenciones basadas en la evidencia que reducen la morbilidad y la mortalidad por trauma en Bolivia.

Importancia clínica: Estos resultados califican la carga por trauma en esta región boliviana, y sirven como la base para intervenciones en el futuro para mejorar los resultados de los pacientes lesionados, y reducir su morbilidad y la mortalidad.

Datos masivos: Bolivia, Carga de enfermedad, Fortalecimiento del sistema de salud, Mejora de la calidad, Mundo en desarrollo, Prevención de lesiones, Salud pública, Registro de trauma.

\section{ABSTRACT}

Aim: Trauma is a leading cause of global deaths. Many resource-limited settings, like Bolivia, lack data on injury mechanisms and outcomes, restricting targeted initiatives for prevention and quality improvement. We reviewed initial results from five hospital-based trauma registries in Santa Cruz de la Sierra to explore injury characteristics in this Bolivian region.

Materials and methods: From October 2015 until May 2016 emergency department (ED) staff gathered trauma patient information, including personal and injury demographics, prehospital facts, and hospital disposition, with subsequent transfer into an online platform.

Results: The registry captured $\mathrm{N}=3,220$ patients, of which $64 \%$ were male aged 21 years (IQR 6, 37). Hospital transport occurred via private car (37\%), taxi (23\%), or ambulance $(15 \%)$, with many presenting on the day of injury (74\%) within four hours (52\%). Most injuries occurred at home $(38 \%)$ or in the street $(29 \%)$, were blunt $(64 \%)$, and resulted from falls $(43 \%)$, road traffic incidents $(13 \%)$, or dog bites $(8 \%)$. Common classifiable injuries ( $\mathrm{N}=2,874$ ) included head/face/extremity contusions (43\%), extremity fractures (12\%), arm/hand penetrating injuries 
Conclusion: These data suggest trauma patients at registry hospitals frequently are not hospitalized and many injuries are preventable. A more complete trauma representation within the city requires data quality improvement, program expansion, and supplementary data source inclusion. Results will inform health system resource planning and preventative strategies, enabling evidence-based interventions that reduce injury morbidity and mortality in Bolivia.

Clinical significance: These results qualify the injury burden in this Bolivian region, serving as the basis for future interventions to improve injured patient outcomes, and reduce morbidity and mortality.

Keywords: Big data, Bolivia, Burden of disease, Developing world, Health system strengthening, Injury prevention, Public health, Quality improvement, Trauma registry.

How to cite this article: Boeck MA, South SD, Foianini JE, Toledo G, Camacho JC, Gutiérrez OM, Jauregui L, Mercado P, Haider AH, Swaroop M. Injuries in Bolivia: Initial Trauma Registry Results from Five Hospitals in Santa Cruz de la Sierra. Panam J Trauma Crit Care Emerg Surg 2018;7(3):209-218.

\section{Source of support: Nil}

\section{Conflict of interest: None}

\section{INTRODUCTION}

Trauma is a leading cause of global deaths. Nine-hundred seventy-three million injuries required health facility care in 2013, with 4.8 million resulting in death according to the 2013 Global Burden of Disease (GBD) study. This accounts for an alarming $10.1 \%$ of the $\mathrm{GBD}^{1}{ }^{1}$ with an estimated $90 \%$ of these deaths occurring in low- and middle-income countries (LMICs). ${ }^{2}$ Trauma registries are an evidence-based method for injury data collection and assessment, enabling the analysis of trends and their associations with patient outcomes. Information gathered can be used to determine resource allocation, monitor interventions, and develop prevention practices, among other uses. $^{3}$

However, many resource-limited settings, such as the Plurinational State of Bolivia, lack specific data on injury mechanisms, severities, and outcomes. This deficit severely limits the ability to develop targeted initiatives for trauma prevention and improvements in the quality of care delivered. Despite registry data advances in highincome countries (HICs), LMICs face barriers to obtaining reliable, prospective injury statistics, with a 2013 review finding only 50 registries across 21 LMICs documented in the literature. ${ }^{4}$ Yet data have repeatedly proven critical to developing successful initiatives, such as those at Khon Kaen Hospital in Thailand, where targeted quality improvement interventions in trauma patient care led to a $50 \%$ reduction in mortality. ${ }^{5}$

Using five hospital-based trauma registries in Santa Cruz de la Sierra, this study sought to evaluate initial results and explore inter-hospital differences in patient demographics, injury characteristics, and outcomes in this region of Bolivia. We hypothesized that trauma is a significant cause of morbidity and mortality in this population, and patient characteristics would differ by the hospital due to geographic location and populations served. This information will serve as the initial step to clarifying the quality, quantity, and distribution of injuries in the city of Santa Cruz de la Sierra, providing essential information to health officials on highyield targets for prevention campaigns and quality improvement initiatives.

\section{MATERIALS AND METHODS}

The study took place from October 2015 until May 2016 in the emergency departments (EDs) of five hospitals in Santa Cruz de la Sierra, Bolivia. Institutional Review Board approval was obtained through Northwestern University. The Secretary of Health and Social Policy for the Autonomous Department of Santa Cruz and directors at each of the participating hospitals provided local endorsement due to the absence of formal ethical research boards.

\section{Study Location and Site Selection}

Bolivia is a lower-middle income country located in the heart of South America with a population of 10.9 million people. ${ }^{6}$ The nation is divided into nine departments and 337 municipalities, ${ }^{7}$ with the largest department being Santa Cruz and its capital city of Santa Cruz de la Sierra. Two-point-seven million residents reside in this easternmost, low elevation region known as the country's agro-industrial production center, $82 \%$ of whom live in urban environments. ${ }^{89}$ In the 1960s the city was designed using traditional, early 20th-century European style with a central plaza and colonial grid layout surrounded by rings connected via radial streets (Fig. 1). ${ }^{10}$ The initial proposal stopped at four rings, but with rapid, largely unrestricted and unplanned urbanization since the 1970s, the city has grown to its current state of 12 rings with approximately one to three kilometers between each. In 1995 the city was divided into 12 urban districts, with four additional districts added in 2004 for future growth.,11

Four formal subsectors comprise the Bolivian healthcare system: public, private, social security, and traditional medicine. The public component is divided into three levels of care. The first level includes health posts and health centers, while the second consists of basic hospitals providing pediatric, gynecologic and obstetric, general medical, anesthetic, dental, and surgical care, analogous to district hospitals in other locations. Third level facilities are general hospitals or specialized institutes that provide a complete range of services or 


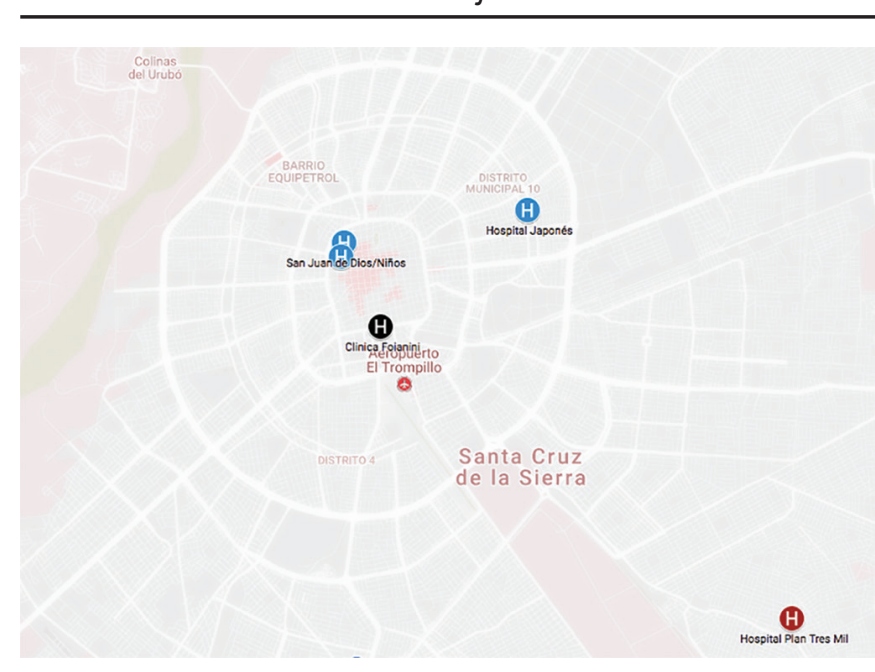

Fig. 1: Map of Participating Hospitals, Santa Cruz de la Sierra, Bolivia ${ }^{10}$

Icons: Blue-Third level hospital; Red-Second level hospital; BlackPrivate hospital

expert care within a given specialty. ${ }^{12,13}$ These institutions are currently managed under a decentralized system, with departmental health services supervising third level facilities, while first and second level centers are overseen by the municipality, ${ }_{14}^{14}$ laying the groundwork for potential coordination conflicts between levels of care. As of 2016, the department of Santa Cruz had the second highest number of healthcare facilities $(\mathrm{N}=687)$ after La Paz, and the most hospital beds $(\mathrm{N}=6,459)$. Despite Santa Cruz having the most people per healthcare establishment $(\mathrm{N}=4,481)$, they fell to sixth for individuals per hospital (second and third level facilities) at 30,785 people per facility. ${ }^{15}$

In collaboration with local health officials and hospital personnel, five hospitals were selected for the initial trauma registry program, based on the common belief that these facilities collectively receive the majority of trauma patients in the city (Table 1). Three of the hospitals are centrally located within or at the first ring, while Hospital Universitario Japonés is situated in the east at the third ring, and Hospital Municipal Plan Tres Mil is located near the sixth ring (Fig. 1).

\section{Trauma Registry Program Implementation}

The selected trauma registry model was developed by the Panamerican Trauma Society (PTS) and has been described in detail elsewhere. ${ }^{16}$ Ongoing data collection form revisions were completed as suggestions or conflicts arose, to better reflect local dialects, subjects of interest, or improve ease of form use and adherence (Fig. 2). The form reflected variables in a web-based platform, which remained unchanged throughout the study. Upon entry into the electronic system, each subject was automatically assigned a unique numerical identifier. The initial registry form had 36 variables, with full name, specific injury mechanism, address, respiratory rate and qualifier, Glasgow coma score (GCS) and qualifier, and injury(ies) with body part(s) collapsed into one variable each. Of these, 29 (80.5\%) were deemed the minimum necessary for registry completion (hospital, date and time of hospital arrival, age, sex, referred, city, mode of transport, date and time of injury event, location of injury event, activity when injured, primary injury mechanism, specific injury mechanism(s), heart rate, blood pressure, respiratory rate, GCS, alert, voice, pain, unresponsive (AVPU) score, use of alcohol, injury(ies) and body part(s), number of serious injuries, ED disposition, date and time of ED disposition, hospital disposition, date and time of hospital discharge, final diagnoses).

Multiple stakeholder meetings took place with hospital and ED directors, local site champions, and health department officials, to ensure the development of a culturally relevant, setting appropriate, sustainable trauma registry program. This conversation was informed by lessons learned from the pilot trauma registry at Clínica Foianini. ${ }^{16}$ All of these efforts culminated in the creation of a departmental policy instructing mutual participation of the selected hospitals in the trauma registry program. Subsequent meetings and training sessions were held at each participating site with select staff responsible for trauma registry implementation. Facility visits also included logistical planning for trauma registry tasks to optimize success within each hospital's unique layout and standard operating procedures. Stakeholders at each site participated in focused qualitative interviews investigating overall hospital function and standard trauma patient management, and quantitative assessments with validated surgical capacity measurement tools (unpublished data). The project lead maintained direct, frequent contact with

Table 1: Trauma registry participating hospitals

\begin{tabular}{lllll}
\hline Hospital & Type/Level & Beds $^{a}$ & Patient population & No. records N=3,220; $N(\%)$ \\
\hline Cliníca Foianini & Private & 50 & All ages, male/female & $831(25.8)$ \\
Hospital Municipal Plan Tres Mil & Public/Second & 146 & All ages, male/female & $189(5.8)$ \\
Hospital Universitario Japones & Public/Third & 200 & All ages, male/female & $585(18.2)$ \\
Hospital de Niños & Public/Third & 120 & Up to 12 years old, male/female & $712(22.1)$ \\
Hospital San Juan de Dios & Public/Third & 244 & $\begin{array}{l}\text { 13 years and older, male/female, } \\
\text { excluding pregnant patients }\end{array}$ & $903(28.0)$ \\
\hline
\end{tabular}

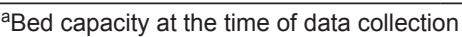


Hospital:

Formulario del Registro de Trauma de la Sociedad Panamericana de Trauma - Bolivia

Datos Demográficos - Nombre:

Apellido paterno:

Apellido materno:

EE 1 No. de historia clínica:____ EE 2 Fecha de llegada:________ (dd/mm/as) EE 3 Hora de llegada:

EE 4 Referido/Transferido: $\square$ Si $\square$ No $\square$ No especificado EE 5 Edad: $\square \square$ Años $\square$ Meses EE 6 Sexo: $\square$ M $\square$ F

EE 7.1 Direcciōn:

EE 7.2 Pais:

EE 7.3 Provincia/Estado:

EE 7.4 Cantón/Municipio:

EE 7.5 Ciudad: Pre-Hospitalario

EE 8 Modo de transporte:
\begin{tabular}{|lll}
$\square$ Ambulancia terrestre & $\square$ Auto particular & $\square$ Transporte en tres ruedas \\
$\square$ Ambulancia avión & $\square$ Transporte público \\
\hline Ambulancia helicóptero & $\square$ Motocicleta & $\square$ Policia
\end{tabular}

Evento de Lesión

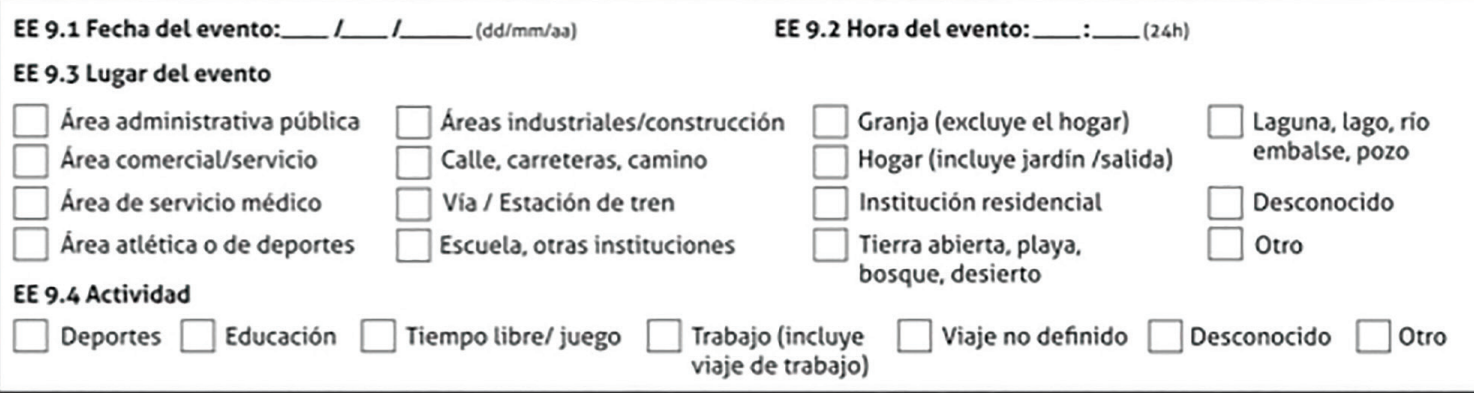

Evento de Lesión

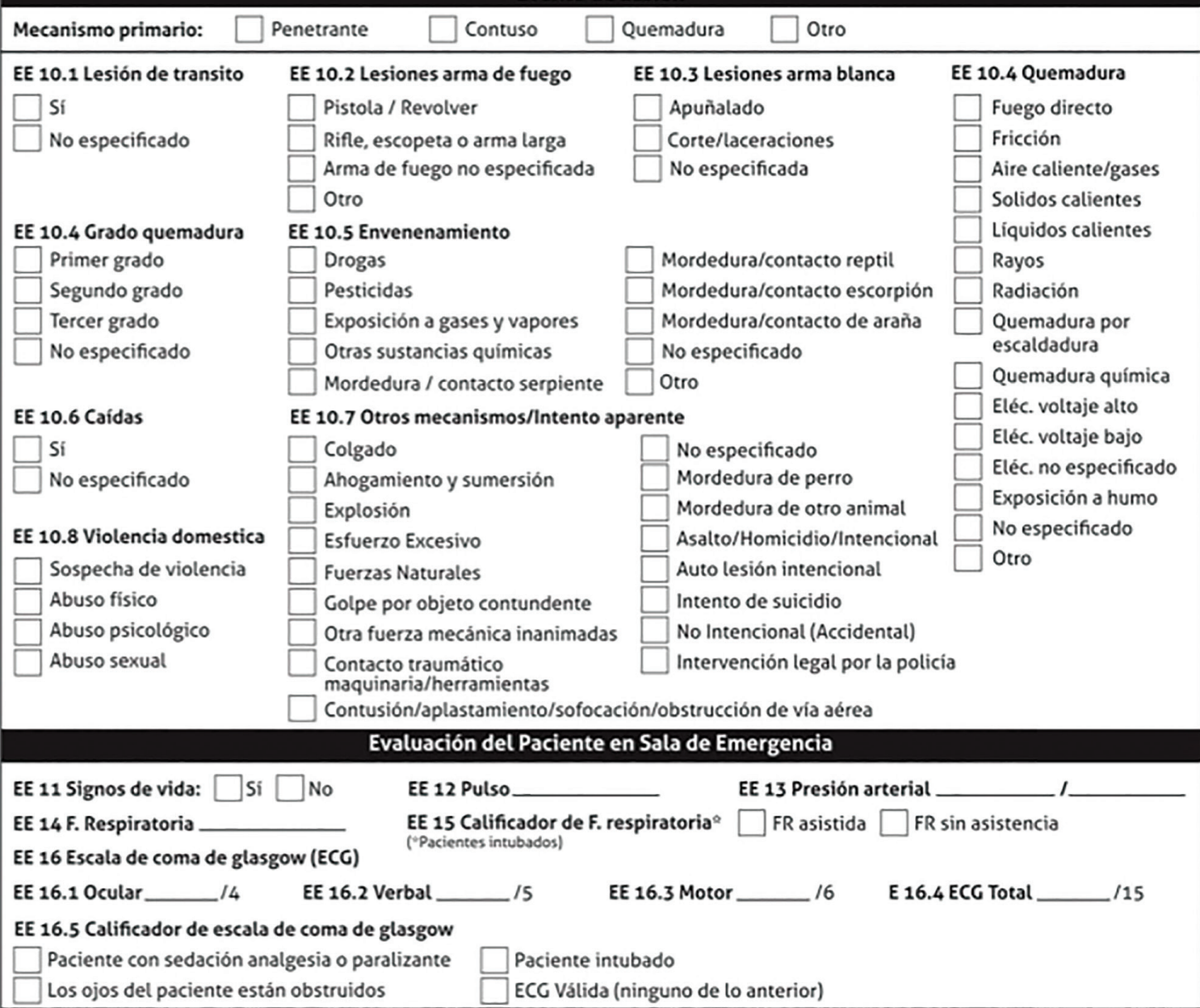

Fig. 2A: Trauma registry form 


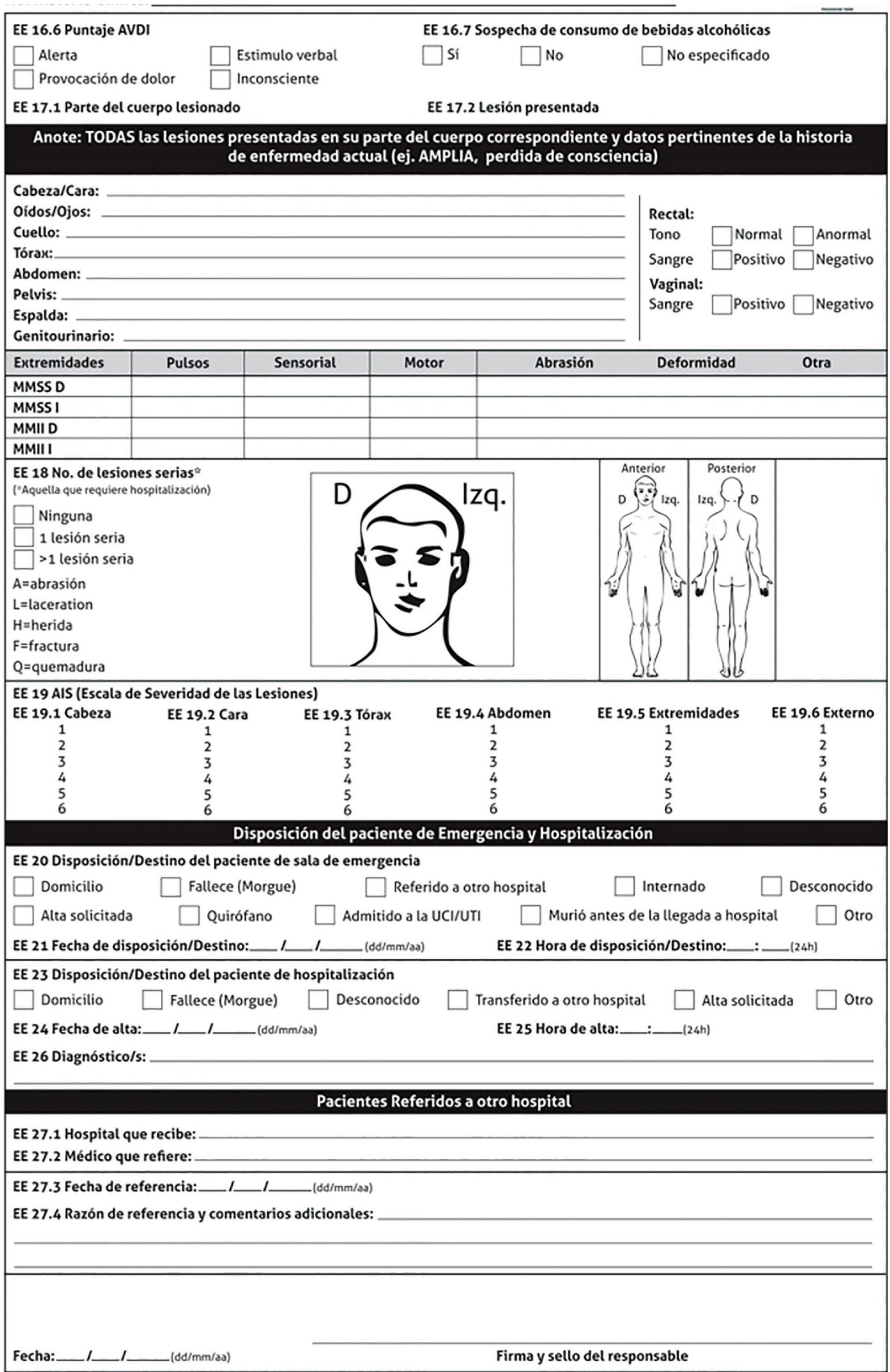

Fig. 2B: Trauma registry form 
site leaders and health department officials for questions or troubleshooting throughout the study period, and performed additional training sessions as requested. Monthly to bimonthly stakeholder meetings reviewed interim results and focused on process improvement to remove any perceived barriers, and celebrate and disseminate successful practices between sites.

\section{Data Collection, Management, and Analysis}

Emergency department (ED) staff at the five participating facilities prospectively identified and recorded trauma patient information on a paper form (initially plain paper, subsequently transitioned to carbon copy) at the time of the patients' initial presentation. Inclusion criteria were patients of any age or gender who presented to the ED of a participating hospital and were deemed by the medical staff to have a traumatic injury. Mechanisms included any acute physical injury by blunt, penetrating, burn, drowning, poisoning, or other miscellaneous forces. All non-trauma patients were excluded from the study. Methods to verify the capture of eligible patients were chosen by designated site leaders, in order to most effectively function within the existing system and improve compliance. Suggested verification practices included ED registration log comparisons, discussions with on-call physicians, and retrospective analyses of registered patient diagnoses by International Classification of Disease codes. If the patient was discharged from the ED, both copies of the form stayed in the ED for subsequent collection. If the patient was admitted to the hospital, the original form stayed in the ED and the copy was placed in the patient's chart for the final data fields to be completed at the time of hospital discharge.

Designated hospital personnel subsequently transferred data from registry paper forms into a password and firewall protected online platform designed and maintained by the PTS. Abbreviated injury scale (AIS) scores and injury severity scores (ISS) were deferred because of an inability to ensure accurate calculations from a lack of data dictionaries, and a consensus between registry leaders that this step would be a significant barrier to form completion.

Data were exported from the web-based registry platform to Microsoft Excel (Microsoft Excel for Mac 2011, Version 14.4.9 Redmond, WA: Microsoft Corporation) for review and cleaning. Double patient entries were collapsed, and data for select blank fields were extrapolated from similar fields by one author (MAB) to decrease missing data. Stata Statistical Software: Release 13 (STATA 13, College Station, TX: Stata Corp LP) was used for data analysis. Per registry design, multiple specific injury mechanisms and injury type/body part could be selected per patient, which were summed into categories and analyzed. Categorical variables were assessed using Chisquared tests, and continuous variables were analyzed by non-parametric methods (Kruskal-Wallis).

\section{RESULTS}

\section{Patient and Injury Demographics}

From October 2015 through May 2016 a total of $\mathrm{N}=3,220$ patients were entered into the trauma registry. Hospital San Juan de Dios had the most trauma registry records $(\mathrm{N}=903,28 \%)$, followed by Clínica Foianini $(\mathrm{N}=831$, $26 \%$ ), and Hospital Universitario Japonés ( $\mathrm{N}=585,18 \%)$ (Table 1). Overall, 64\% were male, the median age was 21 years (IQR 6, 37), and nearly all patients were from the city of Santa Cruz de la Sierra (96.7\%). Hospital de Niños was an outlier, with a median age of four years (IQR 2,7), explained by their intended patient population $(\mathrm{p}<0.001)$. Hospital transport occurred mainly via private car (37.4\%), with most patients presenting on the day of the injury $(73.6 \%)$ within four hours of the inciting event (52.0\%). Most patients at either Hospital Municipal Plan Tres Mil or Clínica Foianini arrived within an hour after the injury event (36.9 and 51.8\%, respectively), while patients largely arrived at the additional three facilities more than four hours since being injured (30.7-34.4\%, p <0.001). Generally, the busiest time for hospital presentation was between 8:00 and 15:59 (44.2\%), followed by $16: 00$ to $23: 59$ (37.2\%). Most injuries occurred at home $(38.5 \%)$ or in the street $(28.8 \%)$, though these proportions differed across hospitals. Fifty-eight-point six percent of patients presenting to Hospital de Niños were injured at home, while those going to Hospital San Juan de Dios were mainly injured in the street $(52.4 \%)$ ( $p<0.001)$. Overall, blunt force trauma was the most common primary mechanism (64.2\%). Notably, Hospital Municipal Plan Tres Mil had nearly double the proportion of penetrating trauma as the other hospitals (30.2\% vs. $11.8-18.5 \%, p<0.001)$. Over one-third of patients presenting to Hospital de Niños and Hospital Universitario Japonés were referrals (39.9\% and 33.2\%, respectively, $\mathrm{p}<0.001$ ). Additional patient demographic information is provided in Table 2.

Themostcommonspecificinjurymechanisms $(\mathrm{N}=3,359)$ were falls $(42.6 \%)$, road traffic incidents $(13.0 \%)$, and dog bites (7.6\%) (Fig. 3). Clínica Foianini had the largest proportion of falls at $62.6 \%$ of all trauma cases, with a median age of 17 years (IQR 5, 40), while road traffic incidents were highest at Hospital San Juan de Dios at $21.6 \%$. Hospital de Niños reported $23.7 \%$ of all injuries as dog bites, where the median age was 6 years (IQR 3, 17), and Hospital Municipal Plan Tres Mil had the biggest share of stabbings at $19.3 \%$ of all injured patients. 
Table 2: Patient demographics

\begin{tabular}{|c|c|c|c|}
\hline Characteristic & & $N=3,220$ & $\%$ \\
\hline $\operatorname{Sex}^{a}$ & Male & 2,065 & 64.1 \\
\hline Age $(\text { years })^{b, c}$ & & 21 & $(6,37)$ \\
\hline Referred/transferred $^{d}$ & Yes & 673 & 20.9 \\
\hline \multirow[t]{6}{*}{ Mode of transport } & Private car & 1,204 & 37.4 \\
\hline & Taxi & 737 & 22.9 \\
\hline & Ambulance & 503 & 15.6 \\
\hline & Public transport & 451 & 14.0 \\
\hline & On foot & 131 & 4.1 \\
\hline & Other ${ }^{\mathrm{e}}$ & 194 & 6.0 \\
\hline \multirow[t]{5}{*}{ Location of injury event } & Home & 1,241 & 38.5 \\
\hline & Street/avenue & 926 & 28.8 \\
\hline & Athletic area & 184 & 5.7 \\
\hline & Commercial/administrative area & 175 & 5.4 \\
\hline & Other ${ }^{f}$ & 694 & 21.6 \\
\hline \multirow[t]{3}{*}{ Primary mechanism ${ }^{g}$} & Blunt & 2,067 & 64.2 \\
\hline & Penetrating & 506 & 15.7 \\
\hline & Burn & 97 & 3.0 \\
\hline Time between injury event and hospital presentation (mins) $)^{\mathrm{b}, \mathrm{h}}$ & & 119 & $(42,540)$ \\
\hline \multirow[t]{3}{*}{ Use of alcoholi } & Yes & 192 & 6.0 \\
\hline & No & 1,828 & 56.8 \\
\hline & Unspecified/blank & 1,200 & 37.3 \\
\hline
\end{tabular}

a. Missing data $1.9 \%$

b. Median (IQR)

c. Missing data $6.8 \%$

d. Missing data $9.1 \%$

e. Bicycle, motorcycle, police, three-wheeler, other, missing data $2.7 \%$

f. School, body of water, open space (beach, forest, desert), train station, medical service area, industrial/construction area, missing data $9.5 \%$

g. Missing data $17.1 \%$

h. Missing data $17.8 \%$

i. Missing data $29.8 \%$

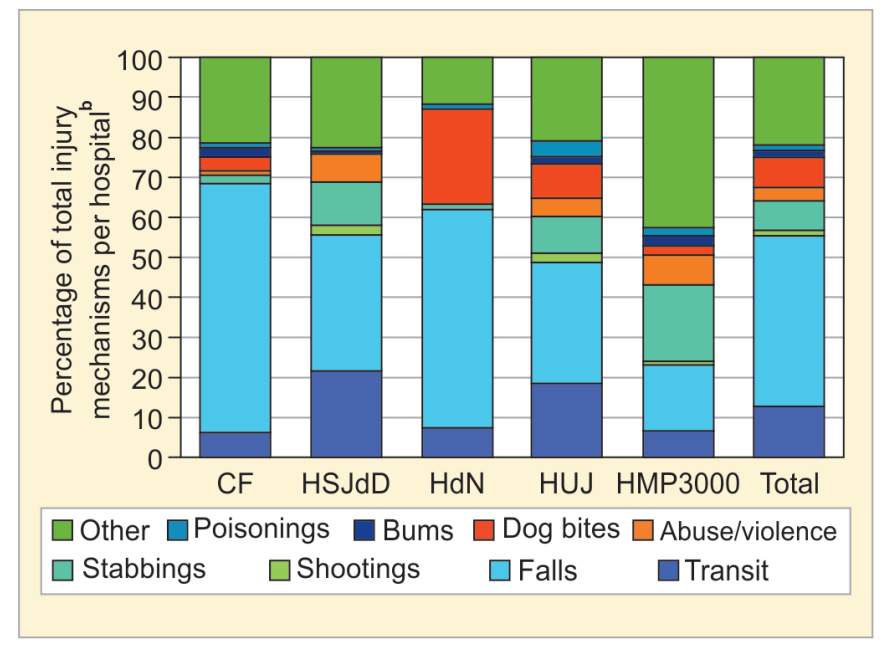

a. $N=3,359$ specific injury mechanisms reported in $\mathrm{N}=3,039(94.4 \%)$ patients; $\mathrm{N}=181(5.6 \%)$ patients without specific injury mechanism recorded;

b. \% of total \# mechanisms reported, with the possibility of multiple mechanisms per patient or no response

- Other: Aggression, drowning, hanging, traumatic contact with a machine, contusion/crush, excessive force, explosion, natural forces, suicide, accident, unspecified, other mechanical forces.

- CF: Clinica Foianini, HSJdD: Hospital San Juan de Dios, HdN: Hospital de Niños, HUJ: Hospital Universitario Japones, HMP3000: Hospital Municipal Plan Tres Mil

Fig. 3: Specific injury mechanisms by hospital ${ }^{a}$

There were $\mathrm{N}=120(3.6 \%)$ cases of abuse or violence documented across all five hospitals, with a $78.6 \%$ male predominance, the median age of 29.5 years (IQR 23.5,
Table 3: Injury location/type ${ }^{a}$

\begin{tabular}{lll}
\hline Injury & $N=2,874^{b}$ & $\%$ \\
\hline Head contusion & 383 & 13.3 \\
Arm/hand contusion & 303 & 10.5 \\
Face contusion & 289 & 10.1 \\
Leg/foot contusion & 270 & 9.4 \\
Arm/hand fracture & 231 & 8.0 \\
Leg/foot fracture & 113 & 3.9 \\
Arm/hand penetrating & 97 & 3.4 \\
Face bite & 89 & 3.1 \\
Face excoriation/laceration & 83 & 2.9 \\
Arm/hand bite & 69 & 2.4 \\
\hline
\end{tabular}

a. Percents are of total number of injury/location types reported, with the possibility of multiple injuries per patient or blank responses

b. $\mathrm{N}=2,874$ injuries in $\mathrm{N}=2,471(76.7 \%)$ patients; $\mathrm{N}=749$ (23.3\%) patients without injuries recorded

38.5), and the largest share of total trauma cases being at Hospital Municipal Plan Tres Mil (19.3\%). The most common injuries recorded $(\mathrm{N}=2,874)$ included head/ face or extremity contusions $(43.3 \%)$, extremity fractures $(12.0 \%), \mathrm{arm} / \mathrm{hand}$ penetrating injuries (3.4\%), and facial bite wounds (3.1\%) (Table 3).

\section{Disposition from Emergency Department}

The majority of patients were discharged home from the ED $(62.1 \%)$, with the highest percentages at Clínica 
Foianini (80.1\%) and Hospital Municipal Plan Tres Mil (80.4\%). Eighteen-point-two percent were admitted, either to a general ward $(16.4 \%)$, intensive care unit $(0.60 \%)$ or directly to the operating room (1.3\%). Hospital San Juan de Dios admitted $38.0 \%$ of their trauma patients, the highest percentage. Across all five facilities, $N=91$ patients $(2.8 \%)$ were referred to another hospital, with the majority being from Hospital Universitario Japonés $(\mathrm{N}=66)$. Seventy-nine patients $(2.4 \%)$ left against medical advice, mainly from Hospital San Juan de Dios ( $\mathrm{N}=57$ ) (all $\mathrm{p}<0.001)$.

\section{Deaths}

Six deaths (0.19\%) were reported over eight months, one at both Clínica Foianini and Hospital Universitario Japonés, and two at both Hospital Municipal Plan Tres Mil and Hospital San Juan de Dios. The patients' median age was 54 years (IQR 21, 61), 50\% were female, and four ( $\mathrm{N}=66.7 \%$ ) presented with a Glasgow coma score of 15 (IQR 5, 15). Injuries and mechanisms included one stabbing and dog bite in the leg/foot, three falls, one of which was associated with suffocation/airway obstruction, an additional suffocation/airway obstruction, and one suicide by hanging with neck/spine/back injuries.

\section{DISCUSSION}

During the eight-month study period, the five hospitals enrolled in the trauma registry program in Santa Cruz de la Sierra, Bolivia saw significant numbers of injured patients, with variations between facilities in volume, demographics, injury characteristics, and disposition. Overall, a majority were discharged home from the ED, suggesting lower severity, and many injury mechanisms were preventable, emphasizing potential targets for prevention. These results provide the first data on trauma patients seen at major hospitals in this region of Bolivia.

As the largest hospital in the department, Hospital San Juan de Dios predictably registered the highest number of trauma patients, and also had the top ED disposition percentage for admissions at 38\%; although the majority of patients $(43.3 \%)$ were discharged home. Hospital Universitario Japonés had both high patient referral intake (33.2\%) and ED referral disposition (11.3\%) rates. The former was seen as related to the hospital's location towards the city's periphery, making it accessible for transfers from more rural locations (personal interview, Dr. Jose Carlos Camacho, 2015). The greater number of referrals to other facilities suggests service unavailability, such specialist evaluations. Hospital Municipal Plan Tres Mil, the only second level hospital in the registry program, had the second highest proportion of referrals at $4.8 \%$. As mentioned previously, the Bolivian healthcare system delegates second level facilities to provide care in basic medical disciplines, including surgery, with referrals as needed for specialists and certain predetermined diagnoses. ${ }^{13}$ Based on the low referral rate from the second level hospital, it would appear these facilities are generally capable of managing most trauma patients that present, enabling the delivery of timely, quality care across greater geographic distances versus relying on third level hospitals that are already functioning over capacity. All of the above highlight the critical importance that the department of health services focus on trauma system development through facility capacity designations, and recognition of trauma patient presentation patterns, to effectively allocate adequate and appropriate resources to effectively care for these patient populations.

According to local physicians, the high proportion of stabbings and violent or abusive incidents recorded at Hospital Municipal Plan Tres Mil is related to the facility's location and patient population. Plan Tres Mil (district 8) on the southeastern periphery of the city was created in the early 1980s as a response to flooding of the Río Piraí and the need to relocate 3200 families to this previously undeveloped, remote area. This community, as well as others outside the fourth ring, is known for its population congestion, inappropriate drainage, inadequate roads, and regular flooding, as well as high concentration of poverty. ${ }^{9,11}$ Corroborating our findings, data from the National Statistics Institute (INE) showed two districts were responsible for $60 \%$ of reported cases of violence against women in the city in the first half of 2017, one of which was Plan Tres Mil. Although prevalent alcohol use was mentioned as a risk factor, ${ }^{17}$ our data did not show this. However, $29.8 \%$ of registry entries did not provide data for whether alcohol was a factor in the injury event. This is likely explained by a lack of routine alcohol level blood testing except when requested by law enforcement, as well as a desire for physicians to not complicate patient insurance coverage should this information become public (personal interviews, local Bolivian physicians, 2015). Hospital de Niños reported a significant number of dog bites at $23.7 \%$ of their trauma cases, with the majority (71.7\%) of all dog bites recorded in the registry $(\mathrm{N}=230)$ occurring in the home. These data were anecdotally supported by commentary from physicians and an epidemiologist working in the hospital. These findings on specific, preventable injury mechanisms, which also include a significant number of falls and road traffic incidents, highlight intervention targets for local officials tasked with improving population health and safety, such as those working in departmental and municipal health services, and public safety, among others.

The registry captured fewer deaths than expected over the eight-month study period. Although no 
reliable statistics exist for all trauma mechanisms for comparison, local physician estimates, media coverage, and limited INE statistics on specific injuries indicate higher trauma mortality in Santa Cruz than measured. Based on police data, the INE reported annual deaths from solely road traffic incidents ranging from 144 to 389 for 2011 to 2015 in the department of Santa Cruz, $^{18}$ which likely are themselves underestimates. Explanations for our low mortality rate include the common practice of not registering patients who are dead on hospital arrival, challenges with obtaining final dispositions for admitted patients, the limited sample size of five hospitals, and patients dying at the scene of the injury or in-transit. Solutions to the above include incorporating data from the morgue and first responders into the registry, emphasizing the importance of registering all trauma patients in the registry despite arriving deceased, program expansion to additional facilities that receive trauma patients, and increased oversight of longitudinal data collection for admitted patients.

The main limitation of our study is data quality. Entry delays for the paper forms to web-based platform occurred at most facilities. Although Clínica Foianini was the initial pilot study site, they were the only site without electronic records for both April and May. This was thought to be linked to changes in personnel and data entry responsibility. The other sites were typically one month behind, except Hospital San Juan de Dios, which continued to have nearly real-time data entry. This is likely attributable to their system of registry oversight by the epidemiology department, which includes a continual supply of rotating students for form collection and data entry, serving as a potential model for other sites.

A moderate proportion of minimum necessary registry variables lacked responses, limiting the ability for exact analyses and conclusions. Percentages of missing values ranged from $0 \%$ (e.g. hospital date of arrival, hospital) to $80.8 \%$ (activity when injured). The median percent missing of all required variables was $11.2 \%$ (IQR 2.7, 28.6). This calculation does not include the AVPU score, number of serious injuries, nor the time of hospital discharge, as the electronic system was unable to export these values for analysis. Variables with more than 30\% missing data were excluded from analysis (activity when injured, time of ED disposition, hospital disposition, date of discharge, final diagnoses). Those with the highest proportion of missing data still used were use of alcohol ( $\mathrm{N}=960,29.8 \%)$, injury type/location $(\mathrm{N}=749$, $23.3 \%)$, primary injury mechanism $(\mathrm{N}=550,17.1 \%)$, and calculated difference between injury time and hospital presentation ( $\mathrm{N}=573,17.8 \%$ ), all of which was disclosed in table footnotes. The inclusion of these data despite significant proportions missing was justified based on the presumed randomness of omission. Data were explored, which showed those without alcohol use responses nor primary injury mechanism indicated were younger, with the highest percentage missing at Hospital de Niños (40.7 and $44.7 \%$ respectively), with no differences by sex. Injury type/location identified Hospital San Juan de Dios as an outlier with $51.7 \%$ of patients missing data. Finally, the difference between injury time and hospital presentation was almost universally available at Hospital Municipal Plan Tres Mil (3.2\% missing), without notable differences in age or sex overall. These areas are clearly problematic and require a special focus for improved data quality in the future.

The accuracy of information entered also varied, including documentation of appropriate injury mechanism(s), vital signs, and all relevant injury diagnoses, as well as complete capture of eligible trauma patients into the registry. Overall conclusions regarding patient outcomes were limited by a lack of injury severity score. Technical issues with the registry web platform prevented automatic calculation of the Revised Trauma Score, and missing variables plus technical issues with the web platform limited the calculation of the Kampala Trauma Score. The above items continue to be addressed, via a complete redesign of the web registry program, as well as improved registry quality control under the supervision of a hired administrator.

\section{CONCLUSION}

This study is the first to describe the diverse injury burden in Santa Cruz de la Sierra, Bolivia. Our results suggest trauma patients arriving at registry-enrolled hospitals frequently are not hospitalized, with many injuries stemming from preventable mechanisms. Moving toward a more complete representation of trauma within the city will include data quality improvement, registry program expansion, and supplementary data source inclusion. Results will inform health system resource planning and preventative strategies, enabling the development of evidence-based interventions that effectively address injury morbidity and mortality reduction in Bolivia.

\section{CLINICAL SIGNIFICANCE}

These results begin to quantify and qualify the local injury burden in this region of Bolivia, including between hospital differences, serving as the basis for future public health interventions. These will aim to improve injured patient outcomes through enhanced care quality and to reduce morbidity and mortality via targeted prevention strategies. 


\section{ACKNOWLEDGMENTS}

This study received funding from the Northwestern University Feinberg School of Medicine Postgraduate Fellowship in Global Health, and the Arthur Tracy Cabot Fellowship at the Center for Surgery and Public Health, Brigham and Women's Hospital, Harvard T. H. Chan School of Public Health, and Harvard Medical School. The study received Institutional Review Board Approval from Northwestern University Feinberg School of Medicine, and local Bolivian approval from each of the five participating hospitals and the Autonomous Department of Santa Cruz Secretary for Health and Social Policy. This study would not have been possible without the passion and dedicated efforts of the Secretary for Health and Social Policy Dr. Óscar Urenda, the director of the Department of Health for the Department of Santa Cruz Dr. Joaquin Monasterio, local health official Dr Alia Aguilera, and numerous additional health department and hospital personnel, all of whom saw the value in this endeavor and believed that changing the system was possible in the name of improving population health. Additional thanks to Dr. Michel Aboutanos and Dr. Lina Mata at Virginia Commonwealth University, who provided limitless registry technical and methodological support to facilitate implementation.

\section{REFERENCES}

1. Haagsma JA, Graetz N, Bolliger I, Naghavi M, Higashi $H$, Mullany EC, et al. The global burden of injury: incidence, mortality, disability-adjusted life years and time trends from the Global Burden of Disease study 2013. Inj Prev. 2016 Feb;22(1):3-18.

2. Injuries and violence: the facts. Geneva: World Health Organization, 2010

3. Nwomeh BC, Lowell W, Kable R, Haley K, Ameh EA. History and development of trauma registry: lessons from developed to developing countries. World J Emerg Surg. 2006;1:32.

4. O'Reilly GM, Joshipura M, Cameron PA, Gruen R. Trauma registries in developing countries: a review of the published experience. Injury. 2013 Jun;44(6):713-21.
5. Essential Surgery. In: Debas HT, Donkor P, Gawande A, Jamison DT, Kruk ME, Mock CN, editors. Disease Control Priorities 3. Vol. 1. Third edition ed. Washington D.C.: World Bank; 2015.

6. Bolivia: The World Bank Group; 2016 [cited 2018]. Available from: http://data.worldbank.org/country/bolivia.

7. Health in the Americas, 2012 Edition: Country Volume Bolivia. Pan American Health Organization, 2012.

8. Santa Cruz Bolivia: Instituto Nacional de Estadistica; 2015. Available from: http://www.ine.gob.bo/pdf/Bo_Es_Na/ santa_cruz_web.swf.

9. Kirshner JD. City profile: Santa Cruz de la Sierra. Cities. 2013 Apr;31:544-52. PubMed PMID: WOS:000317246900053. English.

10. Santa Cruz de la Sierra: Google Maps; 2018 [cited 2018]. Available from: https://www.google.com/maps/@-17.8062054,63.1783151,13z/data =!3m1!4b1!4m2!6m1!1s18rJXpQuCWdSc 09jMj9ltpud8DMw?hl=en\&authuser=1.

11. Plan Territorial de Desarrollo Integral (PTDI): Santa Cruz de la Sierra 2016-2020. Bolivia: Gobierno Autónomo Municipal, 2016.

12. Health Systems Profile: Bolivia, Monitoring and Analysis Health Systems Change/Reform. Washington D.C.: Pan American Health Organization, World Health Organization, 2007.

13. Norma Nacional de Caracterización de Hospitals de Segundo Nivel de Atencion. Bolivia: Ministerio de Salud y Deportes, 2014 Contract No.: 285.

14. Bolivia Washington DC: Pan American Health Organization; 2017 [cited 2018 May 30]. Available from: https://www.paho. org/salud-en-las-americas-2017; p. 3974.

15. Anuario Estadístico 2016. Bolivia: Instituto Nacional de Estadistica, 2017.

16. Boeck MA, Blair KJ, Foianini JE, Perry HB, Mata LV, Aboutanos MB, et al. Implementation of a Hospital-based Trauma Registry in Santa Cruz de la Sierra, Bolivia: Methodology, Preliminary Results, and Lessons learned. Ivatury RR, editor. Panamerican Journal of Trauma, Critical Care \& Emergency Surgery [Internet]. Jaypee Brothers Medical Publishing; 2016;5(2):101-112.

17. Reportes de violencia contra la mujer: $60 \%$ de casos son en 2 distritos. Bolivia: El Día; 2017.

18. Estadísticas Sociales: Hechos de Tránsito Bolivia: Instituto Nacional de Estadística; 2018 [cited 2018 May 31st]. Available from: https://www.ine.gob.bo/index.php/seguridadciudadana/introduccion-4. 